\title{
A hospital based case control study of female breast cancer risk factors in a Sub-Saharan African country
}

\section{Mamour Gueye*, Serigne Modou Kane Gueye, Mame Diarra Ndiaye Gueye, Moussa Diallo, Oumar Gassama, Babacar Biaye, Ahmed Ould Lemine, Aminata Niasse, Aissatou Mbodji, Jean Charles Moreau}

Department of Obstetrics and Gynaecology, Aristide Le Dantec Teaching Hospital, PO BOX-3001, Pasteur Avenue, Cheikh Anta Diop University, Dakar, Senegal

Received: 17 May 2016

Accepted: 07 June 2016

\section{*Correspondence:}

Dr. Mamour Gueye,

E-mail: mamourmb@yahoo.fr

Copyright: ( ) the author(s), publisher and licensee Medip Academy. This is an open-access article distributed under the terms of the Creative Commons Attribution Non-Commercial License, which permits unrestricted non-commercial use, distribution, and reproduction in any medium, provided the original work is properly cited.

\section{ABSTRACT}

Background: Breast cancer is the most common cancer diagnosed in women worldwide with over 1.3 million new cases per year. There is a wide variation in the geographical burden of the disease with the highest incidences seen in the developed regions of the world and the lowest incidences observed in the least developed regions. The objective of this study was to understand further the risks for breast cancer in Senegalese population which can then inform public health strategies to try and reduce the burden of breast cancer.

Methods: This matched case control study was conducted in 2015 in Aristide Le Dantec Teaching Hospital in Dakar. All women with pathologically confirmed primary breast cancer were considered as cases. For each case, 2 agematched women were recruited. We collected and compared demographic factors, family history of breast cancer, socioeconomic variables, reproductive variables (age at menarche, age at first pregnancy and first live birth, parity, menopausal status, duration of breastfeeding), and exogenous hormone use up to 6 months. Odds ratios from univariate logistic regression were used to estimate the relative risk of breast cancer associated with the various factors, and their predictive effects.

Results: In all, 212 women with breast cancer who were diagnosed as having breast cancer and 424 control women were involved in the study. The mean $\pm \mathrm{SD}$ age of cases and controls was $43.37 \pm 11.94$ years (range 18-83 years) and $42.04 \pm 11.08$ years (range 18-84 years), respectively. There were no significant differences between cases and controls with regards to marital status, parity, age at menarche, past oral contraceptive use, age at first last full-term pregnancy and history of breastfeeding. Breast cancer risk was significantly greater in women with a family history of the disease (OR 2.12, 95\% confidence interval [CI] 1.35-3.31). A significant increase in breast cancer was observed among illiterate women compared to educated women (OR 1.27, CI 1.02-1.58), in premenopausal women and those without occupation.

Conclusions: In this study, reproductive factors as early menarche or menopausal status were not associative to the risk of breast cancer and the early age at diagnosis and the positive history of breast cancer suggest a genetic pattern of this disease in Senegalese woman. But this fact is difficult to confirm for financial reasons.

Keywords: Breast cancer, Risk factors, Senegal

\section{INTRODUCTION}

Breast cancer is the most common cancer diagnosed in women worldwide with over 1.3 million new cases per year. There is a wide variation in the geographical burden of the disease with the highest incidences seen in the developed regions of the world and the lowest incidences observed in the least developed regions. ${ }^{1}$ More recently 
the incidence of breast cancer has been observed to be increasing in low income countries and data suggests that over the next twenty years the majority of the increase in the worldwide burden of the disease will be due to rising incidences in these countries.

Amongst women, cervical cancer is still the most frequently diagnosed cancer but breast cancer is now the most commonly diagnosed cancer in urban Senegalese women. The reasons for the recent observed increase in incidence of breast cancer in the Senegalese population are not clearly understood but thought to be largely explained by 'westernisation' of lifestyles and changes in reproductive behaviour.

By conducting a large scale case control study within Senegal we hope to understand further the risks for breast cancer in this population which can then inform public health strategies to try and reduce the burden of disease.

\section{METHODS}

This matched case control study was conducted in 2015 in Aristide Le Dantec Teaching Hospital in the gynaecologic and obstetric department.

\section{Definition of cases and controls}

All women with pathologically confirmed primary breast cancer were considered as cases.

For each case, 2 age-matched (to within 5 years) women were recruited from patients without any history of breast problems or neoplastic diseases who attended the outpatient gynaecology and breast unit clinic. Women with a history of hysterectomy or artificial menopause were excluded from the study.

\section{Sample size calculation}

The appropriate sample size for a population-based survey is determined largely by three factors

- The estimated prevalence of the variable of interestbreast cancer in this instance

- The desired level of confidence and

- The acceptable margin of error

The sample size required was calculated according to the following formula: $\mathrm{n}=\left(\mathrm{t}^{2} \times \mathrm{p}(1-\mathrm{p})\right) / \mathrm{m}^{2}$ where $\mathrm{n}=$ required sample size; $\mathrm{t}=$ confidence level at $95 \%$ (standard value of 1.96); $\mathrm{p}=$ estimated prevalence of breast cancer in our unit; $\mathrm{m}=$ margin of error at $5 \%$ (standard value of 0.05 ).

In our breast unit, it has been estimated that roughly $15 \%$ $(0.15)$ of women are diagnosed for breast cancer. Use of the standard values listed above provides the following calculation.

\section{Calculation}

$\mathrm{n}=\left(1.96^{2} \times .015(1-.015)\right) / 0.05^{2}=195.9$.

Finally 196 women with breast cancer were required to achieve at least $95 \%$ power and 392 controls.

\section{Data collected}

We collected and compared demographic factors, family history of breast cancer, socioeconomic variables, reproductive variables (age at menarche, age at first pregnancy and first live birth, parity, menopausal status, duration of breastfeeding), and exogenous hormone use up to 6 months. Such data were continuously collected for each patient during the first contact with a physician in our electronic database.

\section{Statistical analysis}

Data were analyzed using SPSS, statistical package for social science (version 21.0, SPSS Inc., Chicago, IL, USA).

Odds ratios from univariate logistic regression were used to estimate the relative risk of breast cancer associated with the various factors, and their predictive effects.

A forward multivariate logistic regression model was used for significant associated risk factors and $\mathrm{p}<0.05$ was considered statistically significant.

\section{RESULTS}

In all, 212 women with breast cancer who were diagnosed as having breast cancer and 424 control women were involved in the study.

The mean \pm SD age of cases and controls was $43.37 \pm 11.94$ years (range 18-83 years) and $42.04 \pm 11.08$ years (range 18-84 years), respectively.

There were no significant differences between cases and controls with regards to marital status, parity, age at menarche, past oral contraceptive use, age at first last full-term pregnancy and history of breastfeeding.

There were significant differences between cases and controls with regards to age (except for the age group 40-49 years).

The results of univariate logistic regression analysis are shown in Table 1.

Breast cancer risk was significantly greater in women with a family history of the disease (OR 2.12, 95\% confidence interval [CI] 1.35-3.31). 
A significant increase in breast cancer was observed among illiterate women compared to educated women
(OR 1.27, CI 1.02-1.58), in premenopausal women and those without occupation.

Table 1: Distribution of cases and controls and adjusted odds ratios for breast cancer according to selected variables.

\begin{tabular}{|c|c|c|c|c|}
\hline Variable & Cases n (\%) & Controls n (\%) & OR $(95 \% \mathrm{CI})$ & $\mathbf{P}$ \\
\hline \multicolumn{5}{|l|}{ Age range (years) } \\
\hline$<39$ & $88(30.9)$ & $197(69.1)$ & $0.91(0.58-1.41)$ & 0.000 \\
\hline $40-49$ & $59(34.7)$ & $111(65.3)$ & $1.08(0.67-1.75)$ & 0.13 \\
\hline $50-59$ & $44(32.8)$ & $90(67.2)$ & 1.00 (reference) & \\
\hline$\geq 60$ & $21(44.7)$ & $26(55.3)$ & $1.65(0.83-3.25)$ & 0.000 \\
\hline Mean \pm SD & $43.37 \pm 11.94$ & $42.04 \pm 11.08$ & & \\
\hline Median (range) & $42(18-83)$ & $41(18-84)$ & & \\
\hline \multicolumn{5}{|l|}{ Literacy } \\
\hline Illiterate & $85(40.1)$ & $133(31.4)$ & $1.27(1.02-1.58)$ & 0.018 \\
\hline Educated & $127(59.9)$ & $291(68.6)$ & $0.87(0.76-0.99)$ & \\
\hline \multicolumn{5}{|l|}{ Working status } \\
\hline No & $125(59)$ & $182(42.9)$ & $1.37(1.17-1.60)$ & 0.000 \\
\hline Yes & $87(41)$ & $242(57.1)$ & $0.71(0.6-0.82)$ & \\
\hline \multicolumn{5}{|l|}{ Marital status } \\
\hline Married & $152(71.7)$ & $328(77.4)$ & $0.92(0.83-1.02)$ & \\
\hline Single/widowed/divorced & $60(28.3)$ & $96(22.6)$ & $1.25(0.94-1.64)$ & 0.72 \\
\hline \multicolumn{5}{|l|}{ Menopausal status } \\
\hline Premenopausal & $147(69.3)$ & $316(74.5)$ & $0.93(0.83-1.03)$ & \\
\hline Menopausal & $65(30.7)$ & $108(25.5)$ & $1.20(0.92-1.56)$ & 0.09 \\
\hline \multicolumn{5}{|l|}{ Parity } \\
\hline Nulliparous & $36(17)$ & $85(20)$ & $0.87(0.59-1.20)$ & 0.3 \\
\hline Parous & $176(83)$ & $339(80)$ & $1.03(0.96-1.12)$ & \\
\hline \multicolumn{5}{|l|}{ Contraception } \\
\hline No & $128(60.4)$ & $240(56.6)$ & $1.06(0.93-1.22)$ & \\
\hline Yes & 84 (39.6) & $184(43.4)$ & $0.91(0.74-1.11)$ & 0.3 \\
\hline \multicolumn{5}{|l|}{ Age at menarche (years) } \\
\hline$<12$ & $11(5.2)$ & $12(2.8)$ & $1.83(0.82-4.08)$ & 0.1 \\
\hline$\geq 12$ & $201(94.8)$ & $412(97.2)$ & $0.97(0.94-1.01)$ & \\
\hline \multicolumn{5}{|l|}{ Age of first pregnancy } \\
\hline$\leq 30$ years & $151(85.3)$ & $310(89.1)$ & $0.95(0.89-1.02)$ & \\
\hline$>30$ years & $26(14.7)$ & $38(10.9)$ & $1.34(0.84-2.14)$ & 0.2 \\
\hline \multicolumn{5}{|l|}{ History of breastfeeding } \\
\hline No & $46(21.7)$ & $96(22.6)$ & $0.95(0.7-1.3)$ & 0.8 \\
\hline Yes & $166(78.3)$ & $328(77.4)$ & $1.01(0.92-1.10)$ & \\
\hline \multicolumn{5}{|c|}{ Familial history of breast cancer } \\
\hline No & $177(83.5)$ & $391(92.2)$ & $0.95(0.84-0.96)$ & \\
\hline Yes & $35(16.5)$ & $33(7.8)$ & $2.12(1.35-3.31)$ & 0.001 \\
\hline
\end{tabular}

\section{DISCUSSION}

Breast cancer patients in Senegal are relatively young (mean: 43.3 years), and the findings presented here show that a positive family history of breast cancer, illiteracy, menopausal status and lack of occupation are risk factors for breast cancer in Senegal.
The associations between some known risk factors for breast cancer may differ in Senegal as compared with developed countries, and that familial breast cancer in young Senegalese breast cancer patients deserves further investigation. It strongly suggests genetic influences in breast cancer development in our population. 
There were no significant differences between cases and controls with regards to marital status. Controversial findings are reported in other similar studies where the risk of breast cancer was higher for unmarried women compared with married women. ${ }^{2}$ Being single in Senegalese society is psychosocially stressful. Such psychosocial stress is usually chronic and may have significant effects on health. ${ }^{3}$ Adverse life events like divorce or death of spouse have also been reported as risk factors associated with breast cancer in few other studies. $^{4-7}$

This being a hospital based study; the results may not be applicable to the general population at large. In order to reduce breast cancer mortality effectively, we need to focus our efforts on prevention and early detection through approach to screening our population earlier than age suggested in general.

This study confirms some of the risk factors of the western population but fails to demonstrate many of the other recognized factors in Senegalese women. The lack of difference between parous and nulliparous women was not expected in this study. In a systematic review of breast cancer risks Weir et al. analyzed 10 studies that investigated the relationship between being nulliparous and being parous with the risk of breast cancer. ${ }^{8}$ Overall, their results were consistent with nulliparity being a risk factor for breast cancer, but the level of risk was relatively low. ${ }^{8}$

According to the results there was no association between breastfeeding and breast cancer.

These results are similar to those from several other studies, with case-control and cohort designs. ${ }^{9}$ However, other studies indicated a high protective effect against breast cancer for women who breastfed.

The ability to control breast cancer with hormonal manipulation has been recognized since 1986, when Beatson reported on oophorectomy as a successful treatment for this disease. ${ }^{10}$ Since that time several other epidemiologic, experimental and clinical lines of evidence have developed that also support this concept. It is well established that menstrual factors resulting in exposure of the breast to increased numbers of ovulatory estrogen cycles over a lifetime, such as early menarche, late menopause, and nulliparity can increase the risk of breast cancer. ${ }^{11,12}$

Conversely, bilateral oophorectomy at a young age and interruptions of the menstrual cycle in the form of multiple pregnancies may confer a protective effect. ${ }^{13}$

The impact of pregnancy on the risk of breast cancer is strongest in the case of the first pregnancy occurring at a young age.
In this study, reproductive factors as early menarche or menopausal status were not associative to the risk of breast cancer and the early age at diagnosis and the positive history of breast cancer suggest a genetic pattern of this disease in Senegalese woman. But this fact is difficult to confirm for financial reasons.

The rate of proliferation of the ductal epithelium is normally high after puberty. The hormonal influences associated with pregnancy induce a process of terminal ductal and lobular stem cell differentiation, theoretically rendering the breast more resistant to carcinogenesis. ${ }^{12,13}$

Henderson and colleagues hypothesized that completion of a full-term pregnancy is crucial for this protective effect because the rapid increase in free estradiol during the first trimester of pregnancy is "equivalent to several ovulatory cycles over a relatively short period of time."

They hypothesized that failure to override this estrogenic surge with the subsequent hormonal changes of advanced pregnancy (as occurs with first-trimester abortions) can result in increased risk of breast cancer. ${ }^{14}$

Early evidence that oral contraceptives (OCs) could significantly increase the risk of breast cancer was reported by Pike al. ${ }^{15}$ In their case-control study of 314 breast cancer patients <37 years of age and 314 matched controls, the use of OCs with a relatively high progesterone content for more than 6 years and starting use of OCs before age 25 years were associated with a relative risk of 4.9 for breast cancer development. Since that time, many studies have been conducted in the world attempting to quantify the level of risk of breast cancer conferred by the use of OCs. The results are relatively inconsistent, with some studies demonstrating an increased risk of breast cancer associated with use of OCs, whereas others demonstrate a protective effect associated with the use of OCs. It should be noted that in most studies, the relative risk estimate is close to unity, indicating that any effect of OCs is modest in magnitude.

\section{CONCLUSION}

Partnership with developed countries is needed to improve diagnosis, management and outcomes of patient with breast cancer.

Partnership is not enough to create the opportunity for change, but can enhance such an opportunity when combined with the availability of proven interventions, results from on-going research and involvement of our health system, our pathologists and other care providers.

Funding: No funding sources Conflict of interest: None declared

Ethical approval: The study was approved by the Institutional Ethics Committee 


\section{REFERENCES}

1. Espié M, Hamy AS, Eskenazy S, Cuvier C, Giacchetti S. Épidémiologie du cancer du sein. EMC Gynécologie. 2012;7(4):1-17.

2. Shamsi U, Khan S, Usman S, Soomro S, Azam I. A multicenter matched case control study of breast cancer risk factors among women in Karachi, Pakistan. Asian Pac J Cancer Prev. 2013;14(1):183-8.

3. Guèye SMK, Guèye $M$, Thiam $M$, Diouf $M$, Thiam $\mathrm{MH}$, Moreau JC. Stress et cancer du sein: analyse d'une cohorte de 316 femmes suivies au Centre Hospitalier Universitaire de Dakar (Sénégal). Journal de la SAGO. 2015;16(1):33-7.

4. Jasmin C, Lê MG, Marty P, Herzberg R. Evidence for a link between certain psychological factors and the risk of breast cancer in a case-control study. Psycho-Oncologic Group (P.O.G.). Ann Oncol. 1990;1:22-9.

5. Jacobs J. Early and chronic stress and their relation to breast cancer. Psychol Med. 2000;30:669-78.

6. Fox B. The role of psychological factors in cancer incidence and prognosis. Oncology. 1996;9:245-56.

7. Ginsberg A, Price S, Ingram D, Nottage E. Life events and the risk of breast cancer: a case-control study. Eur J Cancer. 1996;32:2049-52.
8. Weir R, Day P, W A. Risk factors for breast cancer in women. NZHTA Report. 2007;10(2).

9. Tessaro S, Beria JU, Tomasi E, Victora CG. Breast feeding and breast cancer: a case-control study in Southern Brazil. Cad Saude Publica. 2003;19(6):1593-601.

10. Beatson GT. On the treatment of inoperable cases of carcinoma of the mamma: suggestions for a new method of treatment with illustrative cases. Lancet. 1986;2:104-7.

11. Kelsey JL, Gammon MD. The epidemiology of breast cancer. CA Cancer J Clin. 1991;41:147-65.

12. Hulka BS, Liu ET, Lininger RA. Steroid hormones and risk of breast cancer. Cancer. 1994;74:1111-24.

13. Russo J, Tay LK, Russo IH. Differentiation of the mammary gland and susceptibility to carcinogenesis. Breast Cancer Res Treat. 1982;2:5-73.

14. Henderson BE, Ross R, Bernstein L. Estrogens as a cause of human cancer: the richard and hilda rosenthal foundation award lecture. Cancer Res 1988;48:246-53.

15. Pike MC, Henderson BE, Krailo MD. Breast cancer in young women and use of oral contraceptives: possible modifying effect of formulation and age at use. Lancet. 1983;2:926-9.

Cite this article as: Gueye M, Gueye SMK, Gueye MDN, Diallo M, Gassama O, Biaye B, et al. A hospital based case control study of female breast cancer risk factors in a Sub-Saharan African country. Int J Reprod Contracept Obstet Gynecol 2016;5:2328-32. 